\title{
Tourism risk impact on the destination image of Batangas province
}

\author{
Mercado, Armela P. $\bowtie$ \\ Westmead International School, Philippines (armelamercado@gmail.com)
}

Apritado, Jennie Margaret M.

Lyceum of the Philippines University Batangas, Philippines (jmapritado@lpubatangas.edu.ph)

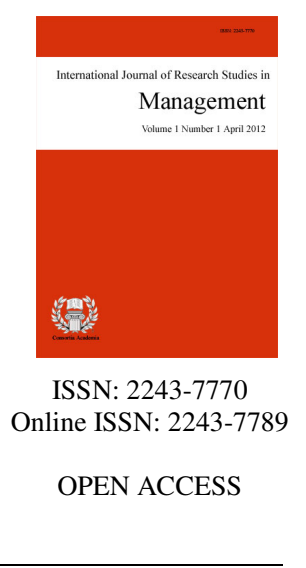

Received: 10 July 2021

Revised: 23 August 2021 DOI: $10.5861 / \mathrm{ijrsm} .2021 . \mathrm{m} 7732$

Accepted: 28 September 2021

\section{Abstract}

Over the past decades, traveling is discretionary spending of an individual or business. Consumers avoid traveling to risky tourism destination and prefer destinations with lowered perceived risks. Tourism risks express of the crises taking many shape and forms in the industry significantly affecting the destination image. The principal aim of the paper was to assess the tourism risk impact on the destination image of the Province of Batangas. Specifically, demographic profile, impact of tourist destination in terms of tourism demand, supply business and destination and policy makers, destination image in terms of man-made, natural disasters, tourist benefits, feeling experience and destination image. A questionnaire was used to collect data from the 437 tourists from top 10 tourist destinations in Batangas Province. Descriptive method was utilized to illustrate the significant relationship between the profile of the respondents and their tourist risk impact on tourist destination. Base on the results, there is high risk impact to tourist destination specifically on destination and policy makers and less impact on the tourism demand, tourism supply businesses. On the other hand, there is also tourist risk impact on the destination image in all given variables such as tourist benefits, destination image, man-made, feeling experience and natural disasters. The result of the study accentuates that tourist destination image can be enhance under the influences of external factors such as increasing awareness of the destination and improving the perception and existing associations in the minds of tourist.

Keywords: destination and policy makers, man-made, natural disasters, tourist benefits, tourism demand 


\section{Tourism risk impact on the destination image of Batangas province}

\section{Introduction}

Tourism, on the whole, is the most important, dynamic, and contributing factor in all economic activity. It has been and continues to be a major driver of economic and social progress. It is also seen as a discretionary sector because the traveler or organization has complete control over their travel plans. Tourism has been on the rise, bringing in the most money for the country's economy. According to the United Nations World Tourism Organization (UNWTO), tourism generated $\$ 1.3$ billion in income in 2020, accounting for $29 \%$ of global services exports and 300 million jobs. It is primarily a major source of money and jobs for both developed and developing countries. Tourism exports total $\$ 1.7$ trillion, accounting for $7 \%$ of global commodity and service trade. Likewise, they account for seven per cent of global trade in goods and services, or $\$ 1.7$ trillion. For Least Developed Countries (LDCs), tourism is also an essential sector contributing 9.5 per cent to their GDP on average.

COVID-19, a global health epidemic, has had a significant influence on international travel. There would be a loss of 850 million to 1.1 billion foreign visitor visits, $\$ 910$ million to $\$ 1.1$ trillion in export income, and 100 to 120 million employments, according to the United Nations World Tourism Organization (UNWTO). The majority of destinations were fully disrupted in April and May 2020. The pandemic has resulted in the unparalleled increase in unemployment. In a similar manner, passenger numbers decrease in considerable levels. The dramatic reduction and need for international travel have increased globally generated weighty difficulties in important businesses, with the cruise and airline sectors being the most affected. In response to the global health problem, countries have encouraged or mandated the adoption of sanitary measures such as hand washing, physical separation, and isolation. The Philippine government has implemented policies like as targeted testing and tracing, lockdowns, public health facility upgrades, and border closures. As a result, the exogenous shocks and uncertainties brought by the pandemic have dulled the enthusiasm for traveling.

As previously mentioned, traveling is a discretionary spending, thus the pandemic deters travel and affects behavior. Yet aside from the current global issue, there are other perceived risks of travel to tourism destinations. Mostly, consumers traveling to high-risk tourism destinations should be avoided in favor of areas with reduced perceived risk hazards. Generally speaking, tourism risks express of the crises taking many shapes and forms in the industry significantly affecting the destination image. Thus, it is imperative for tourism scholars and practitioners to engage in tourism risk management. Risk management encompasses development of policies indispensable for establishing reputation and boosting the tourism brand's equity and awareness, which can attract both international and domestic tourists. Through risk management, tourism companies may include tourist reactions and utilize them constructively way to promote the destination's image. Essentially, destination image mirrors the totality of a tourist's objective views, ideas, and perceptions of a location.

Understanding the tourists' attitudes and concerns towards destinations plays an important role in sustainable tourism. In the same manner, cognizance of tourism risks in the end of management departments can assist in the supervision and effective management of tourist policy, as well as crisis response. The development of a positive impression or image of a destination, as well as the expansion of the tourist destination image, is influenced by public awareness of the location. As a result, the feelings of international tourists develop a favorable relationship between tourism risk and destination image. According to Elain and Siti (2014), travelers' behavioral intentions and future actions are influenced by the destinations themselves.

Batangas stunning land and seascape have long been enticing travelers to experience its beauty firsthand. Like Tagaytay and Zambales, Batangas which is a two-hour drive from Manila, is a typical destination for short and spontaneous getaways. The province of Batangas, which is located in the CALABARZON Region, is rich in 
Filipino culture and tourism. It gives employment and opportunity while also fostering Filipino culture and character. It is known for its beaches, food, and indigenous goods. Tourism has an impact on society, the economy, the environment, culture, and the arts (Aguda et al., 2013). It is a rapidly expanding industry that has come to the top of many countries' economic ambitions. Tourism is thought to aid developing countries in overcoming problems like unemployment and poverty (Phelan et al., 2013).

The risks evident in tourist destinations have been a growing concern of tourism organizations, employees, and tourists. Considerably, these risks can make or break the destination image. In this manner, the researcher being a Tourism Management instructor in a private school in Batangas is interested in investigating the acceptability and tourism risk impact on the destination image of the Province of Batangas. Batangas is a renowned tourist destination in the Metro Manila area. The province is a home to different beaches and is famous for excellent diving spots including Anilao in Mabini, Sombrero Island in Tingloy, and Ligpo Island in Bauan, Likewise, it more popularly known for its Anilao, Matabungkay in Lian, Punta Fuego in Nasugbu, Calatagan and Laiya in San Juan. With its alluring shores, Batangas turns out to be a principal player in the tourism of the Philippines. More importantly, Batangas is home to the Taal Volcano, which is home to Taal Heritage Town, a small picture town with ancestral buildings and architecture dating back to the nineteenth century. The information gathered will be used to provide inputs for upgrading the destination's image. Similarly, the study is regarded as significant because it contributes to the province of Batangas' positive image as a tourist destination.

\subsection{Objective of the Study}

This research study aimed to assess the tourism risk impact on the destination image of the Province of Batangas. Specifically, to present the demographic profile of the respondents in terms of: age, sex, civil status, education, employment status, type of tourist and reason to travel; to assess the impact of risk to tourist destination in terms of: tourism demand, tourism supply business and destinations and policy makers; determine the tourist risk impact on the destination image in terms of: manmade, natural disasters, tourist benefit, feeling experience and destination image; to propose an action plan for disaster risk management of the tourist destination in Batangas Province

\section{Methods}

Research Design - The main objective of this study was to determine the tourism risk impact in destination image of Batangas Province. Descriptive method was utilized to illustrate the significant relationship between the profile of the respondents and their tourist risk impact on tourist destination. It was employed for better understanding of the study and for elaboration of explanation and easy interpretation.

Participant of the study - The participants of the study are the tourists from the top 10 tourist destinations in Batangas Province based on the most recent data of tourist arrival that will be provided by PTCAO. The total number of participants are 437. These respondents were sampled using the availability sampling. The google forms were uploaded to email and messenger to which the researcher sought assistance from known contacts to distribute the questionnaire, hence arriving at 437 respondents all over Batangas province.

Data Gathering Instrument - The researcher employed an adapted questionnaire. Part I included the respondents' demographic profiles such as age, sex, civil status, education, employment status, type of tourist and reason to travel and frequency of travel; On the other side, Part II assessed the impact of risk to tourist destination in terms of: tourism demand, tourism supply business and destinations and policy makers. The instrument was drafted and lifted from the Republic Act (RA) No. 11469 or the Bayanihan to Heal as One Act, (2020). Then Part III determined the tourist risk impact on the destination image in terms of man-made, natural disasters, tourist benefit, feeling experience and destination image. This from the study of Ruan et al. (2017), entitled: Measuring Tourism Risk Impacts on Destination Image. Sustainability. The research instrument 
Mercado, A. P., \& Apritado, J. M. M.

underwent validation through researcher's adviser and two research experts. Pilot testing and reliability was conducted prior to the actual survey to the respondents. The pilot testing employed (number) of respondents. Based on the rule of thumb, the instrument is good and valid to use given the Cronbach alpha result for Tourism Demand (0.727), Supply Business (0.938), Destination and Policy Maker (0.902), Man- Made (0.797), Natural Disasters (0.862), Tourism Benefit (0.818), Feeling Experience (0.929) and Destination Image (0.880).

Data Gathering Procedure - The researcher sought the approval from the Dean of Graduate School of Lyceum of the Philippines - Batangas to conduct the study. Upon receiving the approval, the researcher reached target respondents via referral. The questionnaire was mainly distributed through Google Form and Facebook Messenger. Since questionnaire is distributed through online platforms, the researcher had difficulty retrieving it at the same time. After weeks of waiting for responses.

Data Analysis - After the retrieval of the data from the respondents, it was tabulated and analyzed with scales and formula. The following statistical tools were use in the study: (1) Frequency Count was used to determine the profile of the respondents in terms of age, sex, civil status, education, and employment status, type of tourist and reason to travel and frequency of travel. (2) Percentage was utilized to determine the points and range of the scores of the respondents. It also corresponds to the number or rate that is expressed as a certain number of parts of something or a whole, thus determining the total respondents that fall under certain categories. Also, it expressed the percent of the population and showed the distribution of profiles. (3) Weighted Mean was used to determine the responses of seafarers towards the tourism risks such as man-made, natural disasters, tourist benefit, feeling experience and destination image. Ranking was used to determine the position, or the status of certain situation or condition given along the constructs and variables of the study.

Ethical Consideration - In the conduct of the study, the researcher took into consideration the number of ethical measures. In the conduct of the survey, the personal welfare and interests of participants are protected. This is secured through the research's participants' consent for their involvement in the study. Respondents should participate on the basis of informed consent. The principle of informed consent involves researchers providing sufficient information and assurances about taking part to allow individuals to understand the implications of participation and to reach a fully informed, considered and freely given decision about whether or not to do so, without the exercise of any pressure or coercion. The information about the participants will remain anonymous and confidential. All the methods used to conduct this research were executed in compliance with the requirements of Lyceum of the Philippines University-Batangas.

\section{Result and Discussion}

\section{Table 1}

Demographic profile of the respondents

\begin{tabular}{|c|c|c|}
\hline Age & Frequency & Percentage $(\%)$ \\
\hline 21 or under & 292 & 66.80 \\
\hline $22-31$ & 104 & 23.80 \\
\hline $32-41$ & 25 & 5.70 \\
\hline $42-51$ & 12 & 2.70 \\
\hline $52-61$ & 3 & .70 \\
\hline 62 or above & 1 & .20 \\
\hline \multicolumn{3}{|l|}{ Sex } \\
\hline Male & 135 & 30.90 \\
\hline Female & 302 & 69.10 \\
\hline \multicolumn{3}{|c|}{ Employment Status } \\
\hline Student & 299 & 68.40 \\
\hline Employed & 94 & 21.50 \\
\hline Unemployed & 31 & 7.10 \\
\hline Self-Employed & 13 & 3.00 \\
\hline
\end{tabular}

70 Consortia Academia Publishing (A Partner of Tourism Educators and Movers of the Philippines) 
Tourism risk impact on the destination image of Batangas province

Table 1 ...continued

\begin{tabular}{|c|c|c|}
\hline \multicolumn{3}{|l|}{ Civil Status } \\
\hline Single & 387 & 88.60 \\
\hline Married & 50 & 11.40 \\
\hline \multicolumn{3}{|l|}{ Educational Attainment } \\
\hline College Undergraduate & 278 & 63.60 \\
\hline College Graduate & 95 & 21.70 \\
\hline Post Graduate & 64 & 14.60 \\
\hline \multicolumn{3}{|l|}{ Type of Tourist } \\
\hline Interregional Tourist & 146 & 33.40 \\
\hline Intraregional Tourist & 72 & 16.50 \\
\hline Local Tourist & 219 & 50.10 \\
\hline \multicolumn{3}{|l|}{ Reason for Travel } \\
\hline Business tourist & 28 & 6.40 \\
\hline education travel & 68 & 15.60 \\
\hline Incentive Tourist & 2 & .50 \\
\hline Health and Medical Tourist & 3 & .70 \\
\hline Adventure Tourist & 159 & 36.40 \\
\hline Cultural Tourist & 6 & 1.40 \\
\hline Leisure Tourist & 102 & 23.30 \\
\hline Religious tourist & 6 & 1.40 \\
\hline Shopping tourist & 17 & 3.90 \\
\hline Special Interest Tourist & 41 & 9.40 \\
\hline Sports and recreation tourist & 5 & 1.10 \\
\hline \multicolumn{3}{|l|}{ Frequency of Travel } \\
\hline Always & 35 & 8.00 \\
\hline Generally & 24 & 5.50 \\
\hline Often & 90 & 20.60 \\
\hline Occasionally & 187 & 42.80 \\
\hline Seldom & 92 & 21.10 \\
\hline Never & 9 & 2.10 \\
\hline
\end{tabular}

Among the 437 respondents, majority of the respondents are ages 21 years old and below, female, student, single undergraduate college, local tourist and traveling for adventure occasionally. The results show that females have made travels more than males. Likewise, findings convey that travelling appears to be a growing desire for females. Also, results point out that students are more engaged in travelling than any other status group. It aligns with the results revealed about the most dominant age for travelling. Findings can be attributed to the impression that students find travelling as a means of exposure to activities and experiences they are curious about. They use travel as an avenue of developing themselves and their future careers. As reported by Sheenan et al. (2017), the absence of responsibility for many millennials including students pushes and provides them the opportunity to travel more flexibly, save to travel and also utilize their parents' resources.

The results convey those singles have more time to engage in activities such as travelling. It can also be assumed that they can spend on leisure compared to married. This is for the reason that married couples occupy social and family obligations that stop them to undertake holiday vacation or participate in sports activities. In contrast, Vernon (2010) expressed those married women have more time to involve in leisure than single mothers. Moreover, Data implies that college undergraduates travel more than the other two groups. It can be attributed to the notion that they seek for meaningful and enjoyable experiences that are possible through travels. Results confirm that majority of the respondents seek tourism destinations within their local. It implies that they frequent areas that they may be familiar with. It is also worth noting that respondents choose exotic locations as revealed by the frequency obtained by interregional tourists. It can be presumed that tourists have travel preferences to which they usually engage in. These are somehow consistent with Hassan and Mondal (2013) who underscored that tourist scout for certain attributes prior to their visit of a particular attraction. They generally apportion great value to the issue of safety, security, and accessibility. It can also be inferred those reasons for travel are based on internal force that arouses and pushes an individual from choosing a particular destination with the main goal of 
getting the desired benefits and satisfaction. As revealed, respondents take part in travel because they principally look for an adventure and novelty. These assumptions confirm with Dayour and Adongo, (2015) who accentuated that novelty seeking serves as one among the key determinants tourists who are naturally risk takers travel to new destinations.

Results resonate those respondents have taken travelling as an essential part of unwinding once in a while. However, it is also observed that a little percentage of respondents choose not to travel. This can be rooted to the idea of practicality and safety given the spread of diseases. As Ritchie et al. (2010) postulated people occasionally break free from the daily routine of life through travelling to liberate themselves from tension and anxiety. In a nutshell, aside from the fact that Batangas is two- or three-hour travel from Manila, many are drawn to visit it because of its many features and amazing attractions found within.

Table 2.1

Impact of risk to tourist destination in terms of tourism demand

\begin{tabular}{lccc}
\hline & WM & VI & R \\
\hline 1. I have traumatic experience due to man-made or natural disasters. & 2.41 & Disagree & 5 \\
2. I canceled my trips due to health risk issues; travel restrictions and travel ban. & 3.13 & Agree & 1 \\
3. I feel not worthy in buying tourism product and services at this time of pandemic & 2.68 & Agree & 3 \\
4. My planned travel was affected by trip disruptions. & 3.05 & Agree & 2 \\
5. I loss of travel loyalty and benefits. & 2.46 & Disagree & 4 \\
Composite Mean & 2.75 & Agree \\
\hline
\end{tabular}

Legend: $3.50-4.00=$ Strongly Agree $2.50-3.49=$ Agree $1.50-2.49=$ Disagree $; 1.00-1.49=$ Strongly Disagree

Table 2.1 displays the impact of risk to tourist destination in terms of tourism demand. The composite mean of 2.75 indicates that there was an impact to tourism demand. The item "I canceled my trips due to health risk issues, travel restrictions and travel bans implementations" obtained the highest mean score of 3.13 and assessed as to a great extent. It was followed by my planned travel was affected by trip disruptions and feel not worthy in buying tourism product and services at this time of pandemic with 2.68 and 3.05, respectively. These reveal significant changes in respondents' travel patterns, such as their avoidance of traveling to regions where they perceive hazards. It's hardly surprising, considering the travel restrictions imposed by pandemics. In a similar spirit, travel restrictions and other rules have made it difficult for the ordinary populace to travel. In relation to the findings, Yang et al (2021) explained that because of COVID-19, people will reduce their travel. In case of tourism destinations in Batangas province, they established boundaries and restrictions in order to avoid future conflicts and secure the safety of travelers. Nonetheless, the respondents disagreed on loss of travel loyalty and benefits and have traumatic experience due to man-made or natural disasters that received the lowest mean value of 2.46 and 2.41 respectively. The results articulate that service providers in tourism sectors have positively maintained the loyalty and benefits that are of motivating factors to tourists. Even though tourism is infused with risks, the respondents feel that they receive pleasurable travel experiences. In connection with the findings and as highlighted by Manalo et al., (2015), tourists visiting their local places can adapt and learn valuable things from languages, cultures, to new cuisines helping as well in the nurturing of socio-cultural change.

\section{Table 2.2}

Impact of risk to tourist destination in terms of tourism supply businesses

\begin{tabular}{|c|c|c|c|}
\hline I have experienced to... & WM & VI & $\mathrm{R}$ \\
\hline 1. I underwent health and safety care procedures as I travelled. & 3.31 & Agree & 2 \\
\hline $\begin{array}{l}\text { 2. I received communication regarding travel protocols and updates / health risk protocols } \\
\text { / booking or rebooking process / cancellation or refund process etc. }\end{array}$ & 3.35 & Agree & 1 \\
\hline 3. I was informed about some or modifications on my travel activities or itineraries. & 3.28 & Agree & 3 \\
\hline 4. I was informed about the cancelation of my bookings. & 3.22 & Agree & 4 \\
\hline 5. I was notified about my refund and payments prior my travel. & $\begin{array}{l}3.14 \\
3.26\end{array}$ & $\begin{array}{l}\text { Agree } \\
\text { Agree }\end{array}$ & 5 \\
\hline
\end{tabular}

Legend: $3.50-4.00=$ Strongly Agree; 2.50 - $3.49=$ Agree; $1.50-2.49=$ Disagree; $1.00-1.49=$ Strongly Disagree 
Table 2.2 exhibits the impact of risk to tourist destination in terms of tourism supply businesses with a composite mean of 3.26 that denotes effects of tourism supply businesses. As revealed, the respondents confirmed that they receive communication regarding travel protocols and updates / health risk protocols / booking or rebooking process / cancellation or refund process etc. with the highest weighted mean of 3.35; also they underwent health and safety care procedures as they travelled obtaining a mean of 3.31, and they were informed about some or modifications on travel activities or itineraries with 3.28.

Results establish that the respondents thought travel and tourism businesses have utilized resources necessary in enlightening concerns upon visiting destinations. Likewise, it confirms the tourism sector's aim of removing doubt through promotion of maximum hygiene measures being implemented. It has taken the responsibility for a possibility of change of date or location that might have encouraged travelers and ensure mobility. Furthermore, the strict quarantine measures are employed across Batangas province as a response to the COVID-19 pandemic. For Batangas attractions mostly offering sun, sea and sand, they regard the call for responsibility and for prioritizing safety and security of travelers by putting up management strategies. The findings support Ugur and Akbiyik's (2020) assertion that actors in the tourist sector must take critical efforts to resurrect the industry, including conducting correct risk analyses and implementing adequate crisis management policies, in order to survive.

Further, the respondents showed agreement on being informed about the cancelation of their bookings (3.22) and being notified about refund and payments prior their travel (3.14). Though assessed as agree, they are placed at the fourth and fifth rankings, respectively. The findings specify that travelers are provided refund policies for cancelled travel expenses. Evidently, tourism industry has taken into account the possibility of cancelled trips and refunds. It is inevitable that change in the plan especially during the pandemic may transpire immediately. In some cases, these changes include delayed flight schedule and rebooking, rescheduling of the travel and cancellation of reservation. Although that they create disappointment on both parties between the organizers, tourist service providers, and the tourists, giving more importance in tourists' safety generate confidence and trust and more visitors to come in the future. In light of the findings, Maniga (2020) stressed the need for strong creative, innovation and resilience skills as to put in place innovative solutions to rebuild a sustainable tourism industry.

Table 2.3

Impact of risk to tourist destination in terms of destinations and policy makers

\begin{tabular}{|c|c|c|c|}
\hline Tourist businesses.... & WM & VI & $\mathrm{R}$ \\
\hline 1. I observed the implementation of health and safety protocol for tourists & 3.57 & Strongly Agree & 1 \\
\hline $\begin{array}{l}\text { 2. I fully understand that tourism businesses will manage repatriation of tourists when it is } \\
\text { needed. }\end{array}$ & 3.49 & Agree & 3.5 \\
\hline 3. I clearly understand the policy and guidelines implemented by the tourism businesses. & 3.55 & Strongly Agree & 2 \\
\hline $\begin{array}{l}\text { 4. The standard policy and guidelines on crisis information was disseminated to us during } \\
\text { our tour / travel. }\end{array}$ & 3.46 & Agree & 5 \\
\hline $\begin{array}{l}\text { 5. During my travel I observed that tourism businesses follow the national and local } \\
\text { ordinance. }\end{array}$ & 3.49 & Agree & 3.5 \\
\hline Composite Mean & 3.51 & Strongly Agree & \\
\hline
\end{tabular}

Legend: $3.50-4.00=$ Strongly Agree; 2.50 - 3.49 = Agree; 1.50 - 2.49 = Disagree; 1.00 - $1.49=$ Strongly Disagree

Table 2.3 reveals the impact of risk to tourist destination in terms of destinations and policy makers with the composite mean of 3.51 as verbally interpreted strongly agree, which relates of an impact on the destinations and policy makers. The indicators such as observed the implementation of health and safety protocol for tourists (3.57), understood the policy and guidelines implemented by the tourism businesses (3.55), and understood that tourism businesses will manage repatriation of tourists when it is needed, also observed that tourism businesses follow the national and local ordinance (3.49) top the list, being ranked first to third, respectively. The first two items with highest weighted mean received a verbal interpretation of strongly agree while the third items that land in the same spot are assessed as agree. The findings convey the impressions of safety and health protocols 
disseminated among prospective travelers, thereby playing an important role in the creation of a destination image.

Like the understanding of the travelers of the policies, the tourism sector perceives that its success depends on the implementation and observance of those mentioned indicators. The results confirm the ideas presented by Mair et al. (2016) who emphasized that an effective crisis and a post crisis plan should be put in place both on a regional or national level. The Taal eruption in Batangas and pandemic in January has emptied hotels, campsites, beach resorts, nature and religious attractions in CALABARZON. On the other hand, the respondents' least agreed on the standard policy and guidelines on crisis information being disseminated during tour with 3.46 as the lowest weighted mean. It suggests that tourism businesses might have communicated the crisis information prior to their travel. In the similar manner, it confirms that tourism businesses reiterate the dissemination of guidelines during tour. As reported by Lo et al. (2011), tourism businesses shall develop tourists' risk management strategies including both information related strategies and travel-specific strategies.

\section{Table 3.1}

Tourist risk impact on the destination image in terms of man made

\begin{tabular}{llccc}
\hline & & WM & VI & R \\
\hline 1. & Travel destination alerts affect the choice of my travel destination. & 3.27 & Agree & 2 \\
2. Certain disease control measures in the airport affects my travel choice. & 3.22 & Agree & 3 \\
3. War in travel locations stop me from going there. & 3.21 & Agree & 4 \\
4. Drug-related areas hinder me from choosing the destination. & 3.18 & Agree & 5 \\
5. Peaceful and safe areas influence my choice for travel destination. & 3.56 & Strongly Agree & 1 \\
& & Composite Mean & 3.29 & Agree \\
\hline
\end{tabular}

Legend: 3.50 - 4.00 = Strongly Agree; 2.50 - 3.49 = Agree; 1.50 - 2.49 = Disagree; 1.00 - $1.49=$ Strongly Disagree

Table 3.1 presents the tourist risk impact on the destination image in terms man-made with the composite mean of 3.29, which specifies that there is risk impact on the destination image. Based on the results, the respondents showed strong agreement on the idea that peaceful and safe areas influenced their choice for travel destination (3.56); they agreed that travel destination alerts affect the choice of their travel destination (3.27), and certain disease control measures in the airport affects their travel choice (3.22).

In view of the findings, they insinuate that respondents highly value their need of safety and security as main factors in choosing a travel destination. The Province of Batangas, a part of the CALABARZON Region, is rich in Filipino traditions and tourist destinations. As the province is known for its beaches, food and native products, it has turned to be one of the most popular tourist destinations near Metro Manila. However, in time of pandemic, it has been prompted especially the Beach Tourism the construction of public infrastructure and facilities to cope to ensure visitors' safety including parking, mechanical cleaning, and lifeguarding. As Chiu and Lin (2011) cited, when tourists feel unsecured, they will hesitate to visit the place. Furthermore, results disclose the paramount importance of the tourists' perception of risk in their decision-making process. Thus, possibility of an exposure to undesirable events and emotions might affect travel decision.

Furthermore, the respondents agreed that war in travel locations stopped them from going (3.21), and drug-related areas hindered them from choosing the destination (3.18). Both indicators were placed in the fourth and fifth ranks, respectively. In view of these results, they articulate that destination choice is connected to positive emotion attached to safety and security. Respondents might carry bad impressions to tourism destinations where there are reports by media or tourism alert by government about local tourism crimes. In terms of crime, George (2010) stated that the most common fears among travelers to South Africa were assault and theft. All tourist sites, including those in Batangas province, place a premium on personal safety and security. It is typical for both local and international tourists to be concerned about safety and security. Several people have anxiety of the possible harm or injury they might have during their visit. The thought of tourist's becoming a possible victim to any crime, accidents or terrorism is horrendous. The image of the tourist destination may become disagreeable and unfavorable if the perception of the tourists about that place is dangerous.

74 Consortia Academia Publishing (A Partner of Tourism Educators and Movers of the Philippines) 


\section{Table 3.2}

Tourist risk impact on the destination image in terms of natural disasters

\begin{tabular}{llccc}
\hline & WM & VI & R \\
\hline 1. Damage from natural disasters affects my travel desire. & 3.17 & Agree & 3.5 \\
2. The risk of natural disaster has a negative effect on my choice for location. & 3.17 & Agree & 3.5 \\
3. The potential diseases caused by a natural disaster affect my travel desire. & 3.24 & Agree & 1.5 \\
4. The social instability caused by a natural disaster affects my travel desire. & 3.24 & Agree & 1.5 \\
& Composite Mean & 3.21 & Agree & \\
\hline Legend: $3.50-4.00=$ Strongly Agree; $2.50-3.49=$ Agree; $1.50-2.49=$ Disagree; $1.00-1.49=$ Strongly Disagree & &
\end{tabular}

Table 3.2 displays the tourist risk impact on the destination image in terms of natural disasters with the composite mean of 3.21 suggesting that there is an impact on the destination image present with natural disasters. The top indicators as agreed by the respondents were potential diseases caused by a natural disaster, and social instability affects their travel desire (3.24).

It can be presumed that occurrence of natural disaster may deter tourists' travel intentions. It shows that the high risk of disaster in the destination discourages respondents from visiting it. It is also perceived that geographical location as well as political and economic status of the city, its level of urbanity or rurality may or may not affect the impressions of the visitors towards the attractions. Though the attractions may be feasible but when the location's environment doesn't conform to its feasibility, it will not win visitors. In agreement, Ritchie et al. (2010) cited that disastrous event together with the adverse effects would economically threaten, weaken or destroy the competitiveness of tourist destinations.

In addition, as revealed by the results, damage from natural disasters affects their travel desire, and the risk of natural disaster has a negative effect on my choice for location (3.17) are both agreed by the respondents. Results can be inferred that threat of a natural disaster create impact on people travel decision, though natural disasters are considered unpredictable. However, in the case of Volcano Tourism in Batangas province, tourists are drawn to visit it as they are after knowledge-volcano and novelty seeking. Likewise, most tourists nowadays highly valued physicality of the nature-based attraction especially if it induces knowledge. They aspire such to have a good viewing in order to capture the nature-made scenery for them. Cabral (2016) also noted that San Juan, Batangas, is one of the greatest spots to visit in the province because it caters to beach lovers with its world-class white sand beaches. Aside from the natural features, it has been regarded as a secure location because the town's officials are aware about natural and human-caused calamities such as floods, fires, typhoons, and landslides.

\section{Table 3.3}

Tourist risk impact on the destination image in terms of tourist benefit

\begin{tabular}{|c|c|c|c|}
\hline & WM & VI & $\mathrm{R}$ \\
\hline 1. Tourist is worth studying influences my decision for the choice of tourist destination. & 3.38 & Agree & 2 \\
\hline 2. Unrestricted airspace affects my desire for travel. & 3.17 & Agree & 4 \\
\hline 3. Analyzing tourist benefit is significant to tourism development. & 3.42 & Agree & 1 \\
\hline 4. Promoting a travel boom correlates with tourist benefit. & 3.36 & Agree & 3 \\
\hline Composite Mean & 3.33 & Agree & \\
\hline
\end{tabular}

Legend: 3.50 - 4.00 = Strongly Agree; 2.50 - 3.49 = Agree; 1.50 - 2.49 = Disagree; 1.00 - $1.49=$ Strongly Disagree

Table 3.3 exhibits the tourist risk impact on the destination image in terms of tourist benefit receiving a composite mean of 3.33 as agreed by the respondents. This relates that there is an impact on the destination image as regards to benefits obtained. Results show that respondents analyzed tourist benefit as significant to tourism development (3.42), followed by tourist benefit from the tourism industry worth studying influences decision for the choice of tourist destination (3.38); likewise, they agreed that promoting a travel boom correlates with tourist benefit (3.36). Results suggest that the tourism benefits encourage respondents to increase the positive feelings about the destination image, thereby impact their decision for travel. In same manner, the negative effect on tourist benefit perception influences the destination image. Thus, as posited by George and 
Mercado, A. P., \& Apritado, J. M. M.

Swart (2012), it is imperative to conform to external attributes as to promoting destination's reputation.

Yet, the unrestricted airspace affecting their desire for travel acquired the least weighted mean of 3.17 and assessed as agree. Results affirm that respondents are after comfort when traveling from mode of transportation to the destination. In relation to the findings, Almeyda-Ibanez and George, (2017) emphasized that destination shall represent the promise of a memorable travel experience. It is also worth noting that in the study of Valdez (2019), Batangas attractions are easily discovered and located given the visible road signage.

\section{Table 3.4}

Tourist risk impact on the destination image in terms offeeling experience

\begin{tabular}{llccc}
\hline & & WM & VI & R \\
\hline 1. & Travel protocols affect my travel perception & 3.16 & Agree & 4 \\
2. & The accuracy of travel information affects my travel perception. & 3.21 & Agree & 3 \\
3. Attempting new travel may induce self-exploration for me. & 3.22 & Agree & 2 \\
4. Travel planning may provide different experiences for me. & Composite Mean & 3.24 & Agree & 1 \\
& & Agree & \\
\hline
\end{tabular}

Legend: 3.50 - 4.00 = Strongly Agree; 2.50 - 3.49 = Agree; 1.50 - 2.49 = Disagree; $1.00-1.49=$ Strongly Disagree

Table 3.4 illustrates the tourist risk impact on the destination image in terms of feeling experience with the composite mean of 3.24 as agreed by the respondents. This directs that there is an impact on their feeling of experience upon their visit to the destination. The indicators topping the list and verbally agreed were travel planning may provide different experiences for them (3.38), and attempting new travel may induce self-exploration (3.22).

These express that respondents decide to visit a destination to meet their physiological needs such as health and learning. Likewise, results exhibit the respondents' desire for relaxation and nature exploration through visiting a destination. Thus, tourism directly affects and instigates changes in people's activities, infrastructure, and transportation. According to Kiral'ova and Pavliceka (2015), tourist destinations shall place themselves as real experiences supported by a series of emotional and rational factors. In addition, Boakye (2012) highlighted that the presence of the emotion and past experiences can influence the destination image and, consequently, the travel judgments.

On the other hand, the least indicators agreed by the respondents were accuracy of travel information (3.21) and travel protocols (3.16) affected their travel perception, respectively. The results imply that the effect of the feeling experience on the tourist's destination image evaluation depends on the levels of tourist benefit. Therefore, it can be assumed that the stronger is the positive feeling about the destination, the greater is the will to visit the destination. With regard to the results, Tamajón and Valiente (2017) cited those mental images accumulation about travel experiences from travel promotion advisement, books, movies or general media can influence travel behavior and intention. Good physical features and appearance of destinations and affordable prices of tourist services establish a good impression to the tourists. In the similar manner, Batangas province, being known for its attractions, furnishes tourists more social, emotional, and economic benefits.

\section{Table 3.5}

Tourist risk impact on the destination image in terms of destination image

\begin{tabular}{|c|c|c|c|}
\hline & WM & VI & $\mathrm{R}$ \\
\hline 1. Travel activities affect my tourism perception & 3.27 & Agree & 3 \\
\hline 2. Tourism perceptions may affect my repeated travel. & 3.23 & Agree & 4 \\
\hline 3. Quality of service may improve my original negative images of travel destination & 3.35 & Agree & 1 \\
\hline 4. The creation of tourism perception may improve negative images that a destination has. & 3.32 & Agree & 2 \\
\hline Composite Mean & 3.29 & Agree & \\
\hline
\end{tabular}

Legend: 3.50 - 4.00 = Strongly Agree; 2.50 - 3.49 = Agree; 1.50 - 2.49 = Disagree; 1.00 - $1.49=$ Strongly Disagree

Table 3.5 shows the tourist risk impact on the destination image in terms of destination image with the 
composite mean of 3.29. This establishes that there is a risk impact on the destination image. Respondents acknowledged quality of service improving their original negative images of travel destination (3.35), and creation of tourism perception improving any negative images that a travel destination has (3.32).

As indicated in the results, respondents judged a possibility of turning unfavorable destination image into positive depending on the quality of service and promotion conducted or on the manner it has met tourists' expectations. It is said that customer satisfaction is one of the principal considerations in running a tourist attraction to make it progressive and gain the loyalty of the clients. In a study conducted in La Virginia Hotel Resort in Mataas na Kahoy, Batangas that assessed the level of customer satisfaction with experience in amenities and services of the entire resort management, it cited that majority of the respondents who visited were satisfied in terms of tangibility, reliability, responsiveness, assurance, empathy and facilities/attraction. In support to the findings, Hassan et al. (2010) posited that tourists' satisfaction or dissatisfaction relies on consumption expectations and the discrepancies between them and the actual experience.

In addition, the respondents showed agreement on the least indicators such as travel activities affecting their tourism perception (3.27), and tourism perceptions affecting their repeated travel (3.23). An important point made by the respondents is that their behavior and choice for travelling are dependent on the offers they find at the destination. The attributes such as attractions and activities can impact their behavioral intentions. Backing up this claim, Schaar (2013) emphasized that destination's success relies more on the repeat visits. So, tourism businesses shall work on gaining customers' loyalty. As Moisescu (2018) assumed, loyalty has not only increased awareness of the destination, but has also improves the perceptions and existing associations in the minds of tourists.

Table 5

Proposed action plan for disaster risk management of the tourist destination in Batangas province

\begin{tabular}{ll}
\hline KRA/ Objectives & \multicolumn{2}{c}{ Strategies } \\
\hline \multicolumn{1}{c}{ Impact of Risk to Tourist Destination } \\
\hline To cultivate market through promotion and & $\begin{array}{l}\text { Promotion and Press Releases on } \\
\text { Loyalty Benefits by provide } \\
\text { increased loyalty benefits for both first and } \\
\text { experienced travelers }\end{array}$ \\
$\begin{array}{l}\text { To minimize travel disruptions and cancelation of age groups. } \\
\text { bookings through leveraging social media and } \\
\text { mass media. }\end{array}$ & $\begin{array}{l}\text { Management of Social Media } \\
\text { Accounts }\end{array}$
\end{tabular}

To contribute to the formation and improvement of a destination's image through strict implementation and orientation of protocols coming from the stakeholders and destination residents

To develop strategic communication efforts that will increase awareness of imminent threats as regards to destination.

To collaborate with various tourism stakeholders, including public and private sectors, not-for profit organizations, and local communities.
Coordinated and Integrative Effort from Stakeholders and Local Residents

Establishing Media Relations with the officials at national, regional, and local level founded through Memorandum of Understanding

Partnering with People, LGUs, and NGOs establish through MOA and MOU

Tourists will be enticed to engage in travels given the freebies and benefits that will be provided. Tourists will be enlightened of the possible disruptions or cancellation of bookings as well as be provided information through convenient access to social media and public accounts.

Tourists will be motivated to visit as stakeholders and residents demonstrate strict observance of the protocols.

Tourism managers and potential tourists will be promptly furnished information on threats through media coverage, thereby enhancing their readiness.

The public will be prompted to gain awareness with the convenient and effective flow of information to everyone.

Tourist Risk Impact on the Destination Image To initiate disaster prevention education and Disaster Prevention Education communicate it with tourism experts and the posted and updates on website. public.

To focus on the most essential destination
Travel Reviews/Vlogs through
Tourism businesses will be prepared to control and mitigate consequences of disaster on destination.

\footnotetext{
\begin{tabular}{ll} 
attributes through travel reviews and vlogs media influences & $\begin{array}{l}\text { the destination when the } \\
\text { strengths or attributes of the } \\
\text { destination will be emphasized. }\end{array}$ \\
\hline \hline
\end{tabular}

\begin{tabular}{ll} 
attributes through travel reviews and vlogs media influences & $\begin{array}{l}\text { the destination when the } \\
\text { strengths or attributes of the } \\
\text { destination will be emphasized. }\end{array}$ \\
\hline \hline
\end{tabular}
} 
To develop alternative and new tourism resources; including business areas, products, services, and schemes, that will spark creativity and convenience to the public in spite of the destination being known as prone to disasters

To properly schedule travel time so as to avoid Scheduling Space Travel Time congestion, thus promoting comfort and safety

To eradicate tourists' uncertainties as regards to protocols and provide them comfort through increased safer travel activities

To continue diversifying the activities with increased focus on cultural tourism

\author{
Innovating Tourism Activities \\ through launching of timely \\ activities
}

Managing Tourists' Perceptions needs and analysis and surveys

Tourism Diversification through engaging and fun activities provided for the tourist
Potential tourists amidst risks will be encouraged to engage in travels given the novelty and innovation, destination projects

Potential tourists will be motivated to take trips with the promise of comfort and safety provided by tourism businesses

Potential travelers will be inspired to take travels with novel, explorative yet safe travel activities

Tourists will be furnished with activities that they can during their travel aside from the usual engagements the destination is known for.

\section{Conclusion and Recommendation}

Majority of the respondents are at the age of 21 or under, female students, single. They are college undergraduate, classified as local and adventure tourists. They travelled occasionally. Based on the results, there is high risk impact to tourist destination specifically on destinations and policy makers and less impact on the tourism demand, tourism supply businesses. On the other hand, there is also tourist risk impact on the destination image in all given variables such as tourist benefit, destination image, man-made, feeling experience and natural disasters. There is a significant difference of responses on impact of risk to tourist destination when grouped according to profile specifically on sex, employment status and frequency of travel. Whereas difference of responses on tourist risk impact on the destination image reflected on employment status, educational attainment and reason for travel. There is a highly significant correlation between the impact of risk to tourist destination and tourist risk impact on the destination image in all given variables. The researcher can propose an Action Plan for Disaster Risk Management of the Tourist Destination in Batangas Province.

Tourism sector may step forward in creating and re-creating tourist destination images by improving their safety and security. Tourism business may implement strategic program or security systems that may reduce the risks perceived by the tourists. Tourism business may consider and incorporate the proposed action plan in the conduct of their activities in establishing destination image and people to place connections. The future researchers may utilize mixed method such as quantitative and qualitative efforts including focus group discussion in the analysis of the similar research study. The future researchers may probe similar study using different variables such as tourists' decision making against their choice for destinations.

\section{References}

Aguda, L. A. E., Tamayo, M. R. B., \& Barlan Jr, L. (2013). Effects of heritage tourism to the Municipality of Taal, Batangas, Philippines. Educational Research International, 2(1), 91-95.

Almeyda-Ibáñez, M., \& George, B. P. (2017). The evolution of destination branding: A review of branding literature in tourism. Journal of Tourism, Heritage \& Services Marketing (JTHSM), 3(1), 9-17.

Boakye, K. A. (2012). Tourists' views on safety and vulnerability. A study of some selected towns in Ghana. Tourism Management, 33(2), 327-333. https://doi.org/10.1016/j.tourman.2011.03.013

Cabral, J. V. (2016). Natural and human-induced disasters in San Juan, Batangas: basis for risk reduction management project (Doctoral dissertation, Batangas State University).

Chiu, S. P., \& Lin, S. Y. (2011). Study on risk perceptions of international tourists in India. African Journal of Business Management, 5(7), 2742-2752.

Dayour, F., \& Adongo, C. A. (2015). Why they go there: International tourists' motivations and revisit intention to Northern Ghana. American Journal of Tourism Management, 4(1), 7-17. 
Tourism risk impact on the destination image of Batangas province

Elaine, Y. T. C., \& Siti, A. (2014). Destination image as a mediator between perceived risks and revisit intention: A case of post-disaster Japan. Tourism Management, 40, 382-393. https://doi.org/10.1016/j.tourman.2013.07.008

Garay Tamajón, L., \& Cànoves Valiente, G. (2017). Barcelona seen through the eyes of TripAdvisor: Actors, typologies and components of destination image in social media platforms. Current Issues in Tourism, 20(1), 33-37. https://doi.org/10.1080/13683500.2015.1073229

George, R. (2010). Visitor perceptions of crime-safety and attitudes towards risk: The case of Table Mountain National Park, Cape Town. Tourism management, 31(6), 806-815. https://doi.org/10.1016/j.tourman.2009.08.011

George, R., \& Swart, K. (2012). International tourists' perceptions of crime-risk and their future travel intentions during the 2010 FIFA World Cup in South Africa. Journal of Sport \& Tourism, 17(3), 201-223. https://doi.org/10.1080/14775085.2012.734060

Hassan, M. K., Mondal, A. K. M. G. R., \& Saha, S. K. (2013). Factors affecting the choice of Cox's Baazar sea beach of Bangladesh as a tourist destination. The International journal of management, 2(1), 1-28.

Hassan, S. B., Hamid, M. S. A., \& Bohairy, H. A. (2010). Perception of destination branding measures: a case study of Alexandria destination marketing organizations. International Journal of Euro-Mediterranean Studies, 3(2), 269-288.

Királ'ová, A., \& Pavlíčeka, A. (2015). Development of social media strategies in tourism destination. Procedia-Social and Behavioral Sciences, 175, 358-366. https://doi.org/10.1016/j.sbspro.2015.01.1211

Lo, I. S., McKercher, B., Lo, A., Cheung, C., \& Law, R. (2011). Tourism and online photography. Tourism management, 32(4), 725-731. https://doi.org/10.1016/j.tourman.2010.06.001

Mair, J., Ritchie, B. W., \& Walters, G. (2016). Towards a research agenda for post-disaster and post-crisis recovery strategies for tourist destinations: A narrative review. Current issues in tourism, 19(1), 1-26. https://doi.org/10.1080/13683500.2014.932758

Manalo, I. V., Marayag, D. M., \& Magtibay, Z. K. (2015). Perception on the Impacts of the Development in Brgy. Wawa and Brgy. Boot as Paddling and Beach Destination Centers in La PLaya. LPU_Laguna Journal of International Tourism and Hospitality Management, 128-129.

Maniga, P. (2020). The Impact of COVID-19 on Tourism. Opinion.

Moisescu, O. I. (2018). From perceptual corporate sustainability to customer loyalty: A multi-sectorial investigation in a developing country. Economic research-Ekonomska istraživanja, 31(1), 55-72. https://doi.org/10.1080/1331677X.2017.1421998

Phelan, K. V., Mejia, C., \& Hertzman, J. (2013). The industry experience gap: Hospitality faculty perceptions of the importance of faculty industry experience. Journal of Hospitality \& Tourism Education, 25(3), 123-130. https://doi.org/10.1080/10963758.2013.826950

Ritchie, B. W., Tkaczynski, A., \& Faulks, P. (2010). Understanding the motivation and travel behavior of cycle tourists using involvement profiles. Journal of Travel \& Tourism Marketing, 27(4), 409-425. https://doi.org/10.1080/10548408.2010.481582

Ruan, W. Q., Li, Y. Q., \& Liu, C. H. S. (2017). Measuring tourism risk impacts on destination image. Sustainability, 9(9), 1501.

Schaar, R. (2013). Destination branding: A snapshot. UW-L Journal of Undergraduate Research, 16(1), 1-10.

Sheehan, P., Sweeny, K., Rasmussen, B., Wils, A., Friedman, H. S., Mahon, J., ... \& Laski, L. (2017). Building the foundations for sustainable development: a case for global investment in the capabilities of adolescents. The Lancet, 390(10104), 1792-1806. https://doi.org/10.1016/S0140-6736(17)30872-3

Uğur, N. G., \& Akbıyık, A. (2020). Impacts of COVID-19 on global tourism industry: A cross-regional comparison. Tourism Management Perspectives, 36, 100744. https://doi.org/10.1016/j.tmp.2020.100744

Valdez, E. J. C. (2019). Trends and Issues of Hotel Industry: Impact to the Influx of Tourists in Batangas, Philippines. Asia Pacific Journal of Multidisciplinary Research, 7(3).

Vernon, V. (2010). Marriage: for love, for money... and for time? Review of Economics of the Household, 8(4), 433-457. https://doi.org/10.1007/s11150-009-9086-1 
Mercado, A. P., \& Apritado, J. M. M.

Yang, Y., Cao, M., Cheng, L., Zhai, K., Zhao, X., \& De Vos, J. (2021). Exploring the relationship between the COVID-19 pandemic and changes in travel behaviour: A qualitative study. Transportation Research Interdisciplinary Perspectives, 11, 100450. https://doi.org/10.1016/j.trip.2021.100450 